\title{
Electronic medical record in cardiology: a 10-year Italian experience
}

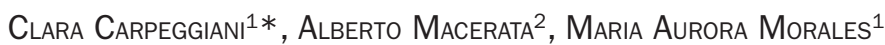 \\ ${ }^{1}$ Medical Doctor - CNR Researcher, National Research Council, Institute of Clinical Physiology of Pisa, Italy \\ ${ }^{2}$ Engineer - Professor at University of Pisa, Pisa, Italy
}

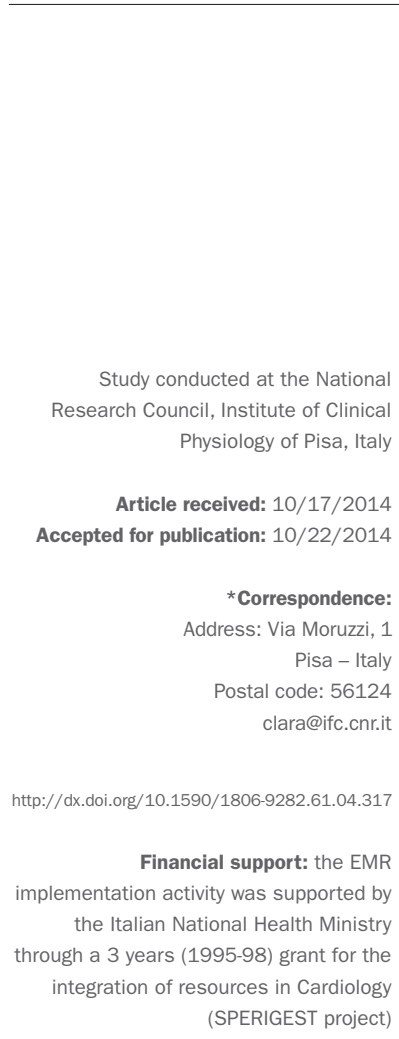

\section{SUMMARY}

Objectives: the aim of this study was to report a ten years experience in the electronic medical record (EMR) use. An estimated $80 \%$ of healthcare transactions are still paper-based.

Methods: an EMR system was built at the end of 1998 in an Italian tertiary care center to achieve total integration among different human and instrumental sources, eliminating paper-based medical records. Physicians and nurses who used EMR system reported their opinions. In particular the hospital activity supported electronically, regarding 4,911 adult patients hospitalized in the 20042008 period, was examined.

Results: the final EMR product integrated multimedia document (text, images, signals). EMR presented for the most part advantages and was well adopted by the personnel. Appropriateness evaluation was also possible for some procedures. Some disadvantages were encountered, such as start-up costs, long time required to learn how to use the tool, little to no standardization between systems and the EMR technology.

Conclusion: the EMR is a strategic goal for clinical system integration to allow a better health care quality. The advantages of the EMR overcome the disadvantages, yielding a positive return on investment to health care organization.

Keywords: electronic health records, cardiology service, hospital.

\section{INTRODUCTION}

The improvement of health care efficiency and effectiveness in the last twenty years has underlined the importance of electronic medical record (EMR) systems. ${ }^{1}$ EMR contributes to a high-quality, efficient patient care, reducing medical errors, promoting standardization of care, ${ }^{2-4}$ as well as obtaining a reduction of costs through the reduction in duplication of services. Although EMR systems have existed for more than 30 years and despite government efforts to promote its use, less than $10 \%$ of hospitals have a fully integrated system and an estimated $80 \%$ of healthcare transactions are still paper-based. ${ }^{5}$ In the United States (USA), the Veterans Administration health care system, with over 155 hospitals, represented the first and largest integrated healthcare delivery systems in the world. ${ }^{6}$ Apart from of the Veterans system, few hospitals had a comprehensive EMR system, some had local information systems, used mainly for administrative rather than clinical purposes. ${ }^{7}$ Since the Obama administration started encouraging providers to adopt electronic health records (EHR), its usage has dramatically increased in the USA and, in 2012, more than $80 \%$ of hospitals have demonstrated meaningful use of EHRs. ${ }^{8}$ Nonetheless, the majority of publications in the field reports slow user acceptance. ${ }^{9,10}$ An EMR system was built at the end of 1998 at the National Research Council Institute of Clinical Physiology (IFC-CNR) in Pisa, Italy, to achieve transparent access to patient data, both administrative and clinical, reaching total integration among different human and instrumental sources, ${ }^{11,12}$ eliminating paper-based medical records. The aim of this study was to describe a long experience ( $>10$ years) in EMR use in cardiology.

\section{Methods}

\section{Network and setting}

A network-based information system interconnected the clinical functionalities and all health care services across the IFC-CNR in Pisa, specialized in cardiopulmonary diseases. The IFC-CNR, in the second half of the 1990s gave 
its priority to electronic data integration, activity supported by the Italian National Health Ministry through a 3-year (1995-98) grant for the integration of resources in Cardiology (SPERIGEST project). ${ }^{12,13}$ In 2007, IFC-CNR healthcare services converged into the CNR-Fondazione Regione Toscana Gabriele Monasterio where the EMR continued to be used. The clinical local area network (LAN) interconnected a Coronary Care Unit (CCU) and two wards (a total of 51 beds), and the outpatient clinic in Pisa. Two cardiac surgery (adult and pediatric ones) and two cardiology departments, with diagnostic laboratories located $60 \mathrm{~km}$ from Pisa, were also integrated in the clinical network system of the institute but are not the topic of this paper. The project was aimed at collecting, archiving and integrating all data related to hospital management, patient administration and care, from the outpatient clinic to hospital admission, diagnostic procedures, intensive care unit, cardiac surgery and, finally, discharge and follow-up.

\section{EMR development}

The EMR was a multimedia collection of data automatically selected from different remote databases, e.g. echo lab, cath lab, chemical lab, nurse system, administration, etc. (Figure 1). A minimum data set of patient/examination for each specific clinical functionality was established, information moving from the local health care unit to the central repository (ARCA). Structured data entry was implemented in addition to free text, whenever authorized by the doctor responsible for the clinical unit. The EMR included: patient demographics, medical history, examination and progress reports of health and illnesses, list of medications and allergies, medical notes, laboratory test results, diagnostic images and reports (X-rays, CTs, MRIs, nuclear medicine, cath lab, echo, etc.), drugs, including side-effects and interactions, discharge letter, nurse record, physicians' notes, administrative functions as hospital discharge record and diagnosis related group (DRG) forms with standard ICD9 codes for diagnoses and procedures (Figure 2). ${ }^{11-13}$ The EMR included a proprietary encoding to identify all diagnosis/procedures not inserted in ICD9 codes (the only recognized by the Italian National Health System) and appropriate transcoding tables to achieve their conversion in ICD9 codes. In the future, the same tables must simply be updated to accept the presence of any new coding systems.

\section{Data analysis}

The authors analyzed health activity related to a five-year time period 2004-2008, when the EMR was fully implemented in Pisa and data were electronically extracted, which included 4,911 adult patients. The following five indicators which seemed relevant to the local setting and to measure the EMR process ${ }^{14}$ were examined:

1. Timely access to medical records: the time lag to access MR for consultation;

2. The readability issue: the amount of comprehensive words;

3. Identification of doctor writing notes /or prescription: amount of readable doctor signatures;

4. Integration with nursing notes derived from the electronic nurses system: the amount of nursing notes integrated in the EMR were reported;

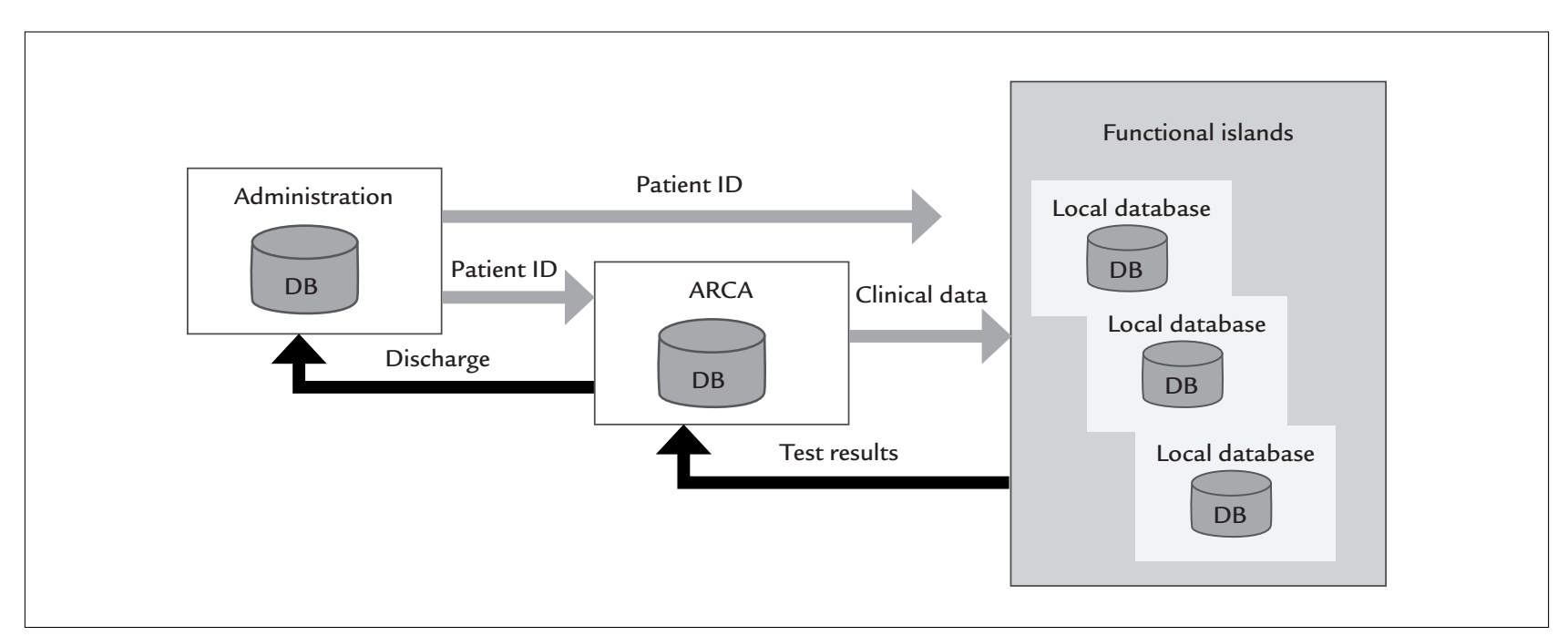

FIGURE 1 Information flow in the clinical system. 


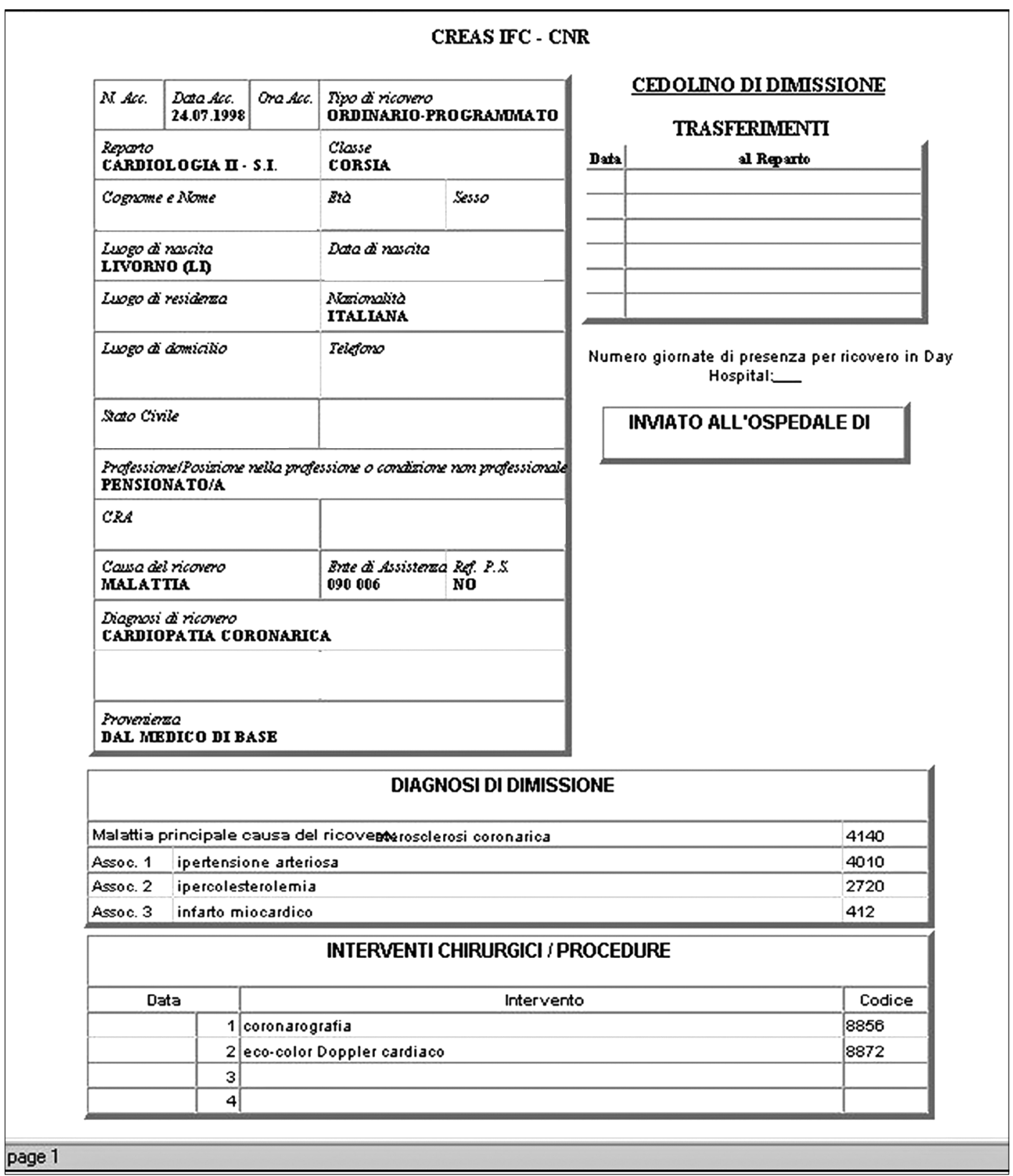

FIGURE 2 Hospital discharge record form with standard ICD9 codes for diagnoses and procedures.

5. Comprehensible description of patient condition: it refers to the capability of understanding the patient's condition by reading the doctor's notes and prescriptions, inserted daily. It was classified as stable/unstable, undetectable.

Audit

Physicians and nurses who used the EMR system were asked to give their opinions, answering on the following points: ease of data entry (yes or no); overall ease of use (yes or no); reliability (yes or no); necessity of training for program and customer support (yes or no); staff satisfaction and patient satisfaction (with answers ranging from "not at all satisfied" to "satisfied" and "completely satisfied"). The study complies with ethical requirements and the Declaration of Helsinki. The informed consent for the use of EMR anonymous personal data for epidemiologic study was obtained at hospitalization.

\section{Results}

EMR had a patient-centered approach supporting medical, nursing and administrative integrated activity. Doc- 
tors, through identity and authorization checking, interacted with the EMR from any workstation over the clinical network. Visualization of all patient admissions to the in or outpatient clinic was available (Figure 3). Predefined text and nomenclatures, as ICD9-CM code, were adopted to characterize cardiac patients' diagnosis and to support the hospital discharge schedule. Registry and structured database were implemented. Clinicians adopted free text data entry more frequently than nurses. External commercial software as the one for chemical lab analyzer was integrated after a period of data control. At the beginning, one out of five lab tests was repeated, since the results were not available at the point of care. Electrocardiograph (ECG) was the last device to be included in the EMR, requiring a further software customization for a complete integration into EMR. Selected ECG devices from one manufacturer only were chosen, according to manufacturer's agreement in supporting device integration. This way, the ECG recordings were sent from the local device to the central database updating the patient clinical record. Cardiologists were in charge of input diagnostic conclusions as soon as the ECG trace was available and physician identity was saved together with ECG examination data. The electron- ic nursing system was integrated and included parameters, such as heart rate, blood pressure, fluid status, respiratory rate, temperature etc., being readily available to physicians. Access to medical records and EMR extraction data was immediate, following the identification control. Readability was clear and doctor identification was always feasible. Comprehensibility of patient condition was adequate, although nurses and doctors notes were scarce.

The large majority of doctors reported being satisfied with EMR; resistance by other users was due to changes in working practice and to EMR time-consuming aspects. All staff considered that EMR was ease to use but required a long training period inversely related to age and computer skill. The need of technical support was underlined by both nurses and doctors. Concern about the temporary loss of access to patient records, secondary to computer or network failure, was expressed by some physicians. Lack of integration with other applications was another complaint. The staff's comments on EMR advantages and disadvantages are summarized in Table 1. Patients verbally reported to nurses and doctors their satisfaction regarding the electronic management of their clinical data.

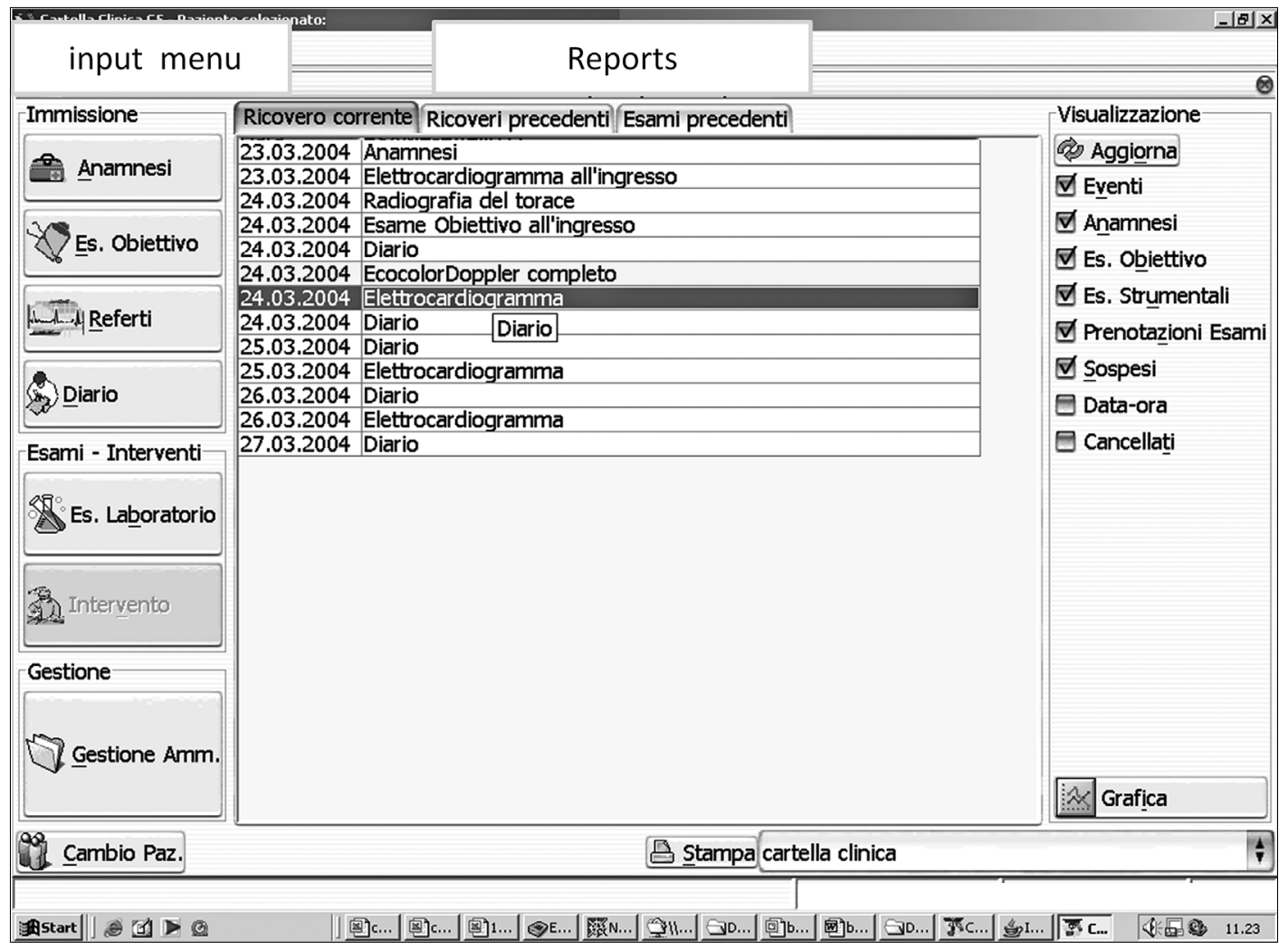

FIGURE 3 Main frame of EMR with the input menu on the left and the list of diagnostic reports and images on the right. 


\section{Discussion}

This study is not bringing new insights into this issue, but it was meant to describe a long positive experience with EMR to encourage its usage, underlining what could be useful to accelerate the road to wider its implementation and adoption. The 10-year experience using EMR offered a unique report of a fully integrated EMR system used in a small European hospital. Widespread use of computerized information systems has been hampered by different barriers including financial and technical matters, lack of interconnectivity and standardization, concern about security, personnel unfamiliarity with technology, need to learn how to use the tool, and doubts on clinical utility ${ }^{15}$ despite the political effort to achieve widespread use of electronic systems. ${ }^{8}$ These disadvantages were underlined also in this experience (Table 1), but the benefits of EMR outweigh the negative aspects. With more complete and quick patient information, health professionals improved practice efficiencies, accuracy of diagnoses and health outcomes. It is reported that as many as 30\% of EMR applications attempts failed over the past years due to physicians dissatisfaction. ${ }^{16,17}$ In this experience, the EMR system was well accepted by the personnel and had a positive effect on the daily medical practice. Researchers as well as clinicians underlined the benefits of EMR implementation. Historical patient digital data were directly available for physicians, facilitating clinical and epidemiological research.

\section{TABLE 1 Main EMR characteristics.}

\begin{tabular}{ll} 
Advantages & Disadvantages \\
\hline Total and ubiquitous availability of & Disruptive element (computer) \\
all patient clinical information & \\
\hline Real time reports from diagnostic & Personnel have to change way \\
laboratories & to work (data input) \\
\hline Logical formats and easy & Difficult integration of \\
consultation of data (trends of vital & diagnostic instrumentation \\
parameters, images sequences, etc) & \\
\hline Fast and safe control of personnel & Difficult integration of \\
work & existing paper documentation \\
\hline Standardization of procedures & Long phase of learning use \\
\hline Easy comparison with historical & Constant presence of \\
data and guidelines & dedicated technicians \\
\hline Increase of readability & High costs \\
\hline Suitability of appropriate & \\
\hline analysis &
\end{tabular}

A special feature of the system was its fast development and software implementation with a strong personnel involvement from the beginning, with solutions that could reduce the staff's work load. As for data entry, free text was allowed, although this reduced data integrity. Structured data were essential for administrative management and statistical analysis, but they required more entry time. On the other hand, the system had to be used in everyday clinical activity, where doctors and nurses had to spend a minimum amount of time to fill out the EMR.

Customization was the major goal of our implementation and modular software architecture was adopted, adapting the user interface and workflow to each specific institution and context. Ease of interface facilitated the effective use in daily activity. The patients' consultation was immediate and allowed to follow all admissions to any department and to access key information, such as the patient's diagnosis and lab results, which is one of the core capabilities that EMR should possess in order to improve quality and efficiency in health care. ${ }^{18}$

A faint legibility in handwritten paper medical records can have adverse medico-legal implications, ${ }^{19}$ and contribute to medical errors, ${ }^{20}$ prescription errors and low quality of communication with other providers and with patients. The Brigham and Women's Hospital in Boston, estimated net savings of $\$ 5$ million to $\$ 10$ million being achieved each year, following installation of a computerized physician order entry system, that reduced serious medication errors by $55 \% .{ }^{21} \mathrm{~A}$ high quality data system to support information and communications protocols could have a beneficial effect on patient treatment. There is a tendency to use short phrases or templates to insert electronic notes, both for doctors and nurses. Patient phenotype details and test prescription details present in some EMR sections, such as echocardiographic section, can allow an appropriate evaluation. ${ }^{22}$

Poor technical support in the follow-up and lack of training are two of the barriers reported in the literature,,$^{15}$ which were partly overcome in this system because it had been built inside the institute. ${ }^{11}$ The need for training (learning period) and the constant presence of dedicated technicians was underlined in our audit. System analysis and computer science has not been an integral part of healthcare training, either for doctors or for most health administrators.

The goal was that old chart patient records from previous admissions would be stored and retrieved in the new EMR. This was partly done in our system, integrating the electronic discharge patient report available since 
1994. Other methods could solve this problem, as the scan of old documents were saved as images,$^{23}$ but it would be time-consuming and it was not performed.

The integration of existing instrumentation, such as echocardiographic instrumentation was a major request from doctors and administrative personnel. It was a critical point not always possible, mainly for the lack of interoperability. ${ }^{24}$ This problem could be solved with the help of the manufacturer, as done previously to introduce ECG and lab results in this system.

Electronic signature, which has been adopted in most national and international standards ${ }^{25}$ was not in use during the reported experience and it was not implemented in our electronic system. Few doctors expressed concern about privacy and security, which is a possible barrier reported for EMR diffusion. Privacy in healthcare applies to both paper and electronic records and the authors followed all Italian government guidelines for privacy in health. Governments have set guidelines that all healthcare organizations will have to comply in regards to electronic health transactions. In the European Union, several Directives of the European Parliament and of the Council protect the processing and free movement of personal data, including purposes of health care. ${ }^{26}$

Most patients were satisfied with the complete and readable documentation offered by EMR. EMR could significantly detract the doctor's attention from the patient. A frozen computer could steal minutes or more from patient care. Some patients reported that doctors had to deal with how to enter data electronically and, thus, had less time for them, although this happened during the first EMR installing phase.

Financial matters were a perceived barrier to widespread implementation of EMRs. According to the Agency for Healthcare Research and Quality's National Resource Center for Health Information technology, ${ }^{27} \mathrm{EMR}$ implementations follow the $80 / 20$ rule; that is, $80 \%$ of the work must be spent on problems regarding management changes, while only $20 \%$ is spent on technical issues. There are a few published estimates of the costs of implementation of EMR hospital systems. Wang et al. have provided a model for estimating the cost, and these include acquisition and implementation costs, slow and uncertain financial payoffs, and disruptive effects on practices. ${ }^{28}$ Start-up cost only accounted for $80 \%$ of the total cost for this system, which was almost 5 billion Euros. The remaining cost was secondary to personnel costs, to train staff and for the maintenance of the system. These amounts were similar to the ones reported in the literature. ${ }^{28}$ Furthermore, software technology advances at a rapid pace. Most software systems required frequent updates, often at a significant ongoing cost and requiring periodically full-scale re-implementation, which disrupted not only the budget but also the workflow. A sufficient number of workstations, laptops, or other mobile computers were installed to accommodate the number of healthcare providers at any one facility, to facilitate the integration of services and to avoid delay in collecting clinical data and missing of information.

EMR systems are estimated to improve efficiency by $6 \%$ per year, and the monthly cost of an EMR can be offset by the cost of only a few unnecessary tests, especially at large hospitals. ${ }^{29} \mathrm{~A}$ cost-offset effect can also derive from a reduction of physical storage of paper documents, which is obtained with EMR implementation. On the other hand, long-term preservation and storage of electronic records has to face other issues, such as the length of the storage, the methods to ensure the future accessibility and compatibility of EMRs archived data, and how to ensure the archives security. One proposal for longterm accessibility and usability of data by future systems could be based on the standardization of the information, such as it is in the XML language. ${ }^{30}$ Medical records must be kept in unaltered form and authenticated by the creator. ${ }^{31} \mathrm{~A}$ lot of technical work was located in this experimental setting to lock EMR at the end of hospitalization. The implementation procedures for security planning involved developing security policies and controls, and implementing tools and techniques to aid in security. An official draft was drawn up.

\section{Conclusion}

EMR has become strategic for clinical system integration, allowing better health care organization. The advantages of the electronic system overcome the disadvantages, yielding a positive return on investment to health care organizations. The home-made EMR development has been critical for the success of the system.

\section{ACKNOWLEDGMENTS}

Authors' contribution statement: $\mathrm{CC}$ and AM conceived the study, wrote the manuscript and are the guarantors of the study; AM performed EMR implementation and data collection. MAM provided expert clinical advice and contributed and commented on drafts of the article.

\section{Resumo}

Registros médicos eletrônicos em cardiologia: uma experiência italiana em 10 anos 
Objetivos: o objetivo deste estudo foi relatar uma experiência de 10 anos de utilização de registro médico eletrônico (EMR). Estima-se que $80 \%$ das transações na saúde ainda são feitas em papel.

Métodos: um sistema de EMR foi implementado ao final de 1998, em um centro italiano de cuidados terciários, com o objetivo de alcançar uma total integração entre diferentes recursos humanos e instrumentais, eliminando registros médicos em papel. Médicos e enfermeiros que utilizaram o sistema EMR relataram suas opiniões. Foi analisada a atividade hospitalar amparada eletronicamente relacionada a 4.911 pacientes adultos hospitalizados, no período de 2004 a 2008.

Resultados: o produto final do EMR integra documentos com recursos de multimídia (texto, imagens, sinais). O EMR apresentou predominantemente vantagens e foi bem adotado pelos profissinais. A avaliação de adequação também foi possível em alguns procedimentos. Algumas desvantagens foram encontradas, como os custos de instalação, longo período de aprendizado para uso, pouca ou nenhuma padronização entre os sistemas EMR. Conclusões: o EMR é um objetivo estratégico para a integração do sistema de clínica e para permitir uma melhor qualidade de cuidados de saúde. As vantagens do EMR superam as desvantagens, produzindo um retorno positivo desse investimento para a instituição de saúde.

Palavras-chave: registros eletrônicos de saúde, serviço hospitalar de cardiologia.

\section{References}

1. Chaudhry B, Wang J, Wu S, Maglione M, Mojica W, Roth E, et al. Systematic review: impact of health information technology on quality, efficiency, and costs of medical care. Ann Intern Med. 2006; 144(10):742-52.

2. Coiera E. The electronic medical record. In: The guide to health informatics. 2.ed. London: Arnold, 2003. p.111-23.

3. Hillestad R, Bigelow J, Bower A, Girosi F, Meili R, Scoville R, et al. Can electronic medical record systems transform health care? Potential health benefits, savings, and costs. Health Aff (Millwood). 2005; 24(5):1103-17.

4. Horning R. Implementing an electronic medical record with computerized prescriber order entry at a critical access hospital. Am J Health Syst Pharm. 2011; 68(23):2288-92.

5. Jha AK, DesRoches CM, Campbell EG, Donelan K, Rao SR, Ferris TG, et al. Use of electronic health records in U.S. hospitals. N Engl J Med. 2009; 360:1628-38.

6. Asch SM, McGlynn EA, Hogan MM, Hayward RA, Shekelle P, Rubenstein $\mathrm{L}$, et al. Comparison of quality of care for patients in the veterans health administration and patients in a national sample. Ann Intern Med. 2004; 141(12):938-45

7. Adler-Milstein J, Bates DW, Jha AK. U.S. Regional Health Information Organizations: progress and challenges. Health Aff(Millwood). 2009; 28:483-92.
8. HHS. Gov. U.S. Department of Health \& Human Services. Doctors and hospitals' use of health IT more than doubles since 2012. More than half of America's doctors have adopted electronic health records. Avaliable at: http://www.hhs.gov/news/press/2013pres/05/20130522a.html.

9. Khaliq AA, Mwachofi AK, Hughes DR, Broyles RW, Wheeler D, Roswell RH. The current state of electronic health record (HER) use in Oklahoma. J Okla State Med Assoc. 2013; 106(2):53-6

10. Kalra D, Fernando B. A review of the empirical evidence of the healthcare benefits of personal health records. Yearb Med Inform. 2013; 8:93-102.

11. Taddei A, Carpeggiani C, Emdin M, Balocchi R, Dalmiani S, Cecchetti G, et al. Development of an electronic medical record for patient care in Cardiology. Computers Cardiol. 1997; 27:641-4. Available at: http://ieeexplore.ieee.org/ stamp/stamp.jsp?arnumber $=898514$.

12. Carpeggiani C, Dalmiani S, Taddei A, Franchi D, Michelassi C, Chelozzi L, et al. Use of electronic medical record in a department of cardiology. Computers Cardiol. 2000; 27:291-4.

13. Dyro JF. Clinical engineering handbook. Burlington: Elsevier, 2004.

14. Longo F, Del Vecchio M, Lega F. La sanità futura. Come cambieranno gli utenti, le istituzioni, i servizi e le tecnologie. Milão: Università Bocconi Editore, 2010.

15. 15.Häyrinen K, Saranto K, Nykänen P. Definition, structure, content, use and impacts of electronic health records: a review of the research literature. Int J Med Inform. 2008; 77(5):291-304.

16. Boonstra A, Broekhuis M. Barriers to the acceptance of electronic medical records by physicians from systematic review to taxonomy and interventions. BMC Health Serv Res. 2010; 10:231.

17. McDonald CJ. The barriers to electronic medical record systems and how to overcome them. J Am Med Inform Assoc. 1997; 4(3):213-21.

18. Tang P. Key capabilities of an electronic health record system. Letter Report. Institute of Medicine Committee on Data Standards for Patient Safety. Board on Health Care Services. Washington (DC): National Academies Press, 2003.

19. Sokol DK, Hettige S. Poor handwriting remains a significant problem in medicine. J R Soc Med. 2006; 99(12):645-6.

20. Lyons R, Payne C, McCabe M, Fielder C. Legibility of doctors' handwriting: quantitative comparative study. BMJ.1998; 317(7162):863-4.

21. Bates DW, Leape LL, Cullen DJ, Laird N, Petersen LA, Teich JM, et al. Effect of computerized physician order entry and a team intervention on prevention of serious medication errors. JAMA. 1998; 280(15):1311-6.

22. Picano E, Pasanisi E, Brown J, Marwick TH. A gatekeeper for the gatekeeper: inappropriate referrals to stress echocardiography. Am Heart J. 2007; 154(2):285-90.

23. Laerum H, Karlsen TH, Faxvaag A. Effects of scanning and eliminating paper-based medical records on hospital physicians' clinical work practice. J Am Med Inform Assoc. 2003; 10(6):588-95.

24. Plotnikov VA, Prilutskii DA, Selishchev SV. The SCP-ECG standard in electrocardiographic software systems. Biomed Eng. 1999; 33(3):128-35.

25. Durmortier J, Kelm S, Nilsson H, Skouma G, Van Eecke P. The legal and market aspects of electronic signatures. Study of the European Commission. October; 2003.

26. European Parliament and Council (24 October 1995): EU Directive 95/46/ EC-The Data Protection Directive Retrieved. July; 2006.

27. Caitlin CM, Poon EG. Health Information Technology Evaluation Toolkit. AHRQ Publication N.08-0005-EF. October; 2007

28. Wang SJ, Middleton B, Prosser LA, Bardon CG, Spurr CD, Carchidi PJ, et al. A cost-benefit analysis of electronic medical records in primary care. Am J Med. 2003; 114(5):397-403.

29. Evans DC, Nichol WP, Perlin JB. Effect of the implementation of an enterprise-wide electronic health record on productivity in the Veterans Health Administration. Health Econ Policy Law. 2006; 1(Pt 2):163-9.

30. Raza Abidi SS, Manickam S. Leveraging XML-based electronic medical records to extract experiential clinical knowledge. An automated approach to generate cases for medical case-based reasoning systems. Int J Med Inform. 2002; 68(1-3):187-203.

31. National Research Council. For the record: protecting electronic health information. Washington (DC), 1997 